\title{
On Globalization and Ethnomathematics
}

\author{
Thomas Varghese (University of Alberta) \\ Daniel P McCusker
}

\begin{abstract}
:
The changes of globalization are forcing educational systems of developing countries to mimic the curricula, teaching methods and assessment tests of highly industrialized nations. Simply copying a curriculum built for a specific culture, however, may not be effective in another culture as mathematics is a product of the culture and socioeconomic system of a particular country. Mathematics teaching that is founded on and built upon the local cultural knowledge and/or the cognitive background can be more effective and will yield more opportunities to marginalized groups. Inclusion of ethnomathematics (everyday mathematics) in the curriculum helps to situate mathematics in real-world contexts. This article identifies some "everyday mathematics" from two southern states of India and explores how it can enrich classroom practices. School mathematics rooted in one's culture, practices and history could reorient the whole context of mathematics education and allow the learner to experience mathematics as a human rather than an abstract activity.
\end{abstract}

\section{Résumé}

Les changements apportés par la mondialisation ont forcé les systèmes d'enseignement des pays en voie de développement à imiter les programmes d'études, les méthodes d'enseignement et d'évaluation des pays déjà industrialisés. Copier tout simplement un programme d'études édifié pour une culture particulière pourrait le rendre inefficace dans une autre culture. Cela arrive surtout dans le cas des mathématiques qui sont le produit de la culture et du système socio-économique propres à ce pays. Un enseignement des mathématiques qui est fondé et bâti sur la connaissance culturelle locale et/ou sur le fond cognitif pourra être plus efficace et procurera plus de chances aux groupes marginalisés. . L'inclusion dans le programme d'études les ethno-mathématiques (mathématiques du peuple) permet de situer les mathématiques dans le contexte du monde réel. Cet article identifie quelques formes de mathématiques du peuple connues dans deux états au Sud de l'Inde et examine comment les utiliser pour enrichir les pratiques d'enseignement. Les mathématiques scolaires ayant leurs racines dans la culture, dans les pratiques et dans l'histoire d'un peuple peut réorienter tout le contexte de l'enseignement des mathématiques et permettre l'apprenant à expérimenter les mathématiques comme une activité plutôt humaine qu'abstraite.

The definitively modern trend of globalization has so radically shaped economy, politics and culture that even describing it in a satisfactory way is problematic. Nevertheless, a few of its causes and effects - which are often one and the same - can be roughly outlined: the obsessive and rigorous development and 
application of technology; schemes of standardization beyond the most ambitious hopes of ancient empire-builders; and the continual merging and integration of systems and corporations, pursued dogmatically and at times even blindly. Although there may be some influential 'globalizers' who follow these directives in a genuine spirit of universal fraternity, most observers would justifiably conclude that the ultimate goal of this frenetic consolidation is the increase of gain. In order for profit to augment, there must be ever greater efficiency in productivity; efficiency, indeed, has presently won for itself the status of a full-fledged virtue.

Educators are compelled to investigate how these thoroughgoing changes are influencing the world of learning. Perhaps surprisingly, globalization would appear in some ways to have actually caused a regression in the techniques of teaching. For the sake of streamlining the educational process, it has shifted the focus away from the priority of developing knowledge to the secondary function of assessing the results. Given the seemingly limitless global pool of human resources, finding talent through mass assessment has understandably more appeal to an 'efficient' system than does the patient, innovative nurturing of its growth. And since standards are the essence of assessment, one of the consequences of globalization has been the drive to teach a universal mathematics curriculum in schools (Oldham, 1989; Gates \& Vistro$\mathrm{Yu}, 2003)$. The field of mathematics, perhaps because it is often thought of and presented as neutral, culturally independent and value-free, is even more susceptible to this treatment than others, and so educational systems worldwide are being prompted to mimic and mechanically copy mathematics curricula, teaching methods and assessment tests from each other (Gerdes, 1997).

The conception of mathematics is a reflection of the culture and socioeconomics of any given region (Gates \& Vistro-Yu, 2003), hence using a curriculum designed for one specific culture, however, might not be particularly be inspiring for learners in another culture. Compounding this problem, for most of what is generically called the 'developing world,' is the fact that the source of these 'standard' curricula is, generally speaking, the West. Therefore globalized mathematics education not only places many Asian, African or South American students at an academic disadvantage by using curricula tailored for Western students, but also uncomfortably echoes a colonial past, the long-term effects of which are still being endured in many parts of these same regions. As Dowling (1998) reminded us, the whole system will require a Westerner to reveal to nonWestern students the mathematics inherent in their own, non-Western culture. When a European instructs, he or she does it in European terms, and referring to European mathematicians (Dowling cited in Atweh, Clarkson \& Nebres, 2003).

A prominent example of this is the present-day mathematical education in India, once part of the empire "upon which the sun never set" - an early forerunner of globalization. As in many non-Western countries using Western math curricula, it is generally taught in a narrow context with little concern for its historical and cultural settings. An irrelevant and abstract curriculum,

2 Canadian and International Education Vol. 35 no. 1 - June 2006 
distanced from the lives of the majority, is the typical experience of school children (Rampal, 2003). The main reason for the gap between the curriculum and the lives it should enrich is that the educational system transported to India by its colonial master was not adapted to the socio-cultural context of the subcontinent. The development of schools and institutions was conceived within the British system, not a regional one (Smith 2000; Gates \& Vistro-Yu, 2003; Rampal, 2003). Even in India, where trigonometry was developed, the concept of zero was discovered and the decimal system has its roots, and which once saw mathematics as an instrument of divine intervention (Joseph, 2000), school mathematics is now more or less seen as a European product.

There is evidence from the research done by Anderson (1990) that when non-Western students are taught a culturally focused mathematics curriculum, they exhibit more positive and self-assured attitudes towards mathematics, greater persistence and achievement in algebra courses, and greater rates of participation in subsequent mathematics courses when compared to their peers. Every practicing teacher is keenly aware of how important interest is to success in learning; it is so powerful, in fact, that the presence of interest in a subject almost obviates the need for discipline. It is internally rather than externally motivating. In mathematics, as in all subjects, interest is best generated by relating the concepts to everyday life, and this paper suggests certain opportunities that could allow this to happen. It is believed that mathematics education that is relevant and referent to the local socio-cultural context might work miracles of learning in rural and marginalized populations such as those of India.

\section{Ethnomathematics}

The idea of ethnomathematics was developed to incorporate a broader view of how mathematics relates to the real world. It is a relatively new area of mathematics education, beginning with the contributions of the Brazilian educator Ubiratan D’Ambrosio (Knijnik, 1997). The essence of ethnomathematics lies in the fact that there are distinctions between cultures. As Ascher noted (1991), differences such as where people live (deserts or islands or the Artic), how they produce food (hunting, fishing or farming) and many others affect the expression and content of their mathematical ideas. Above all, no single distinction will preclude the mathematical ideas or determine what they will be (Ascher, 1991).

Mathematical activities form a significant part of peoples' everyday lives, even among unschooled communities of India (Rampal, 2003). Through cultural tools and symbolic systems, even non-literates are capable of sophisticated mental computations. As Ascher (1991) states, mathematical ideas are not "the exclusive province of some unusual few who were specially endowed at birth or specially educated" (p.188).

Rampal (2003) noted that, in India, oral numeracy is more natural among unschooled adults than literacy. That means even unschooled are more familiar with numbers, operations and measurements than with letters. 
Therefore, there is no doubt that the children will also be familiar with the every day mathematics their parents use. D’Ambrosio (1985) believes that children acquire the mathematical knowledge of their cultural group at a very young age. However, when they begin to attend school on a regular basis, this knowledge is replaced with school knowledge, which is more valued by the system. The inclusion of ethnomathematics (everyday mathematics) in the curriculum helps mathematics educators move in a direction that situates mathematics in real world contexts. This will be in line with the National Council of Teachers of Mathematics (NCTM) recommendations of 1989. Hence it is worth exploring how "everyday mathematics" can enrich classroom practices.

\section{Everyday Mathematics}

The everyday lives and activities of a society are largely neglected by mathematics education researchers as sites for mathematical knowledge development and use (O’Donoghue, 2000). Many forms of mathematics exist in society side by side with the academic. The forms of mathematics that are embedded in cultural activities, i.e. everyday mathematics such as street marketing and house building, also fall under the category of ethnomathematics (D’Ambrosio, 1993). Moschkovich \& Brenner (2002) defined everyday mathematics as those mathematical practices that adults or children engage in. Bishop (1988) identified six basic activities which can be referred to as "everyday mathematics": counting, locating, measuring, designing, playing and explaining. These out-of-school practices help shed light on ways to improve the teaching and learning of in-school mathematics. Pinxten (1987) noted that if mathematics teaching is founded and built upon the local cultural knowledge and/or cognitive background, it can be more effective and will yield more educational opportunities to marginalized groups.

O’Donoghue (2000) noted that an ethnomathematics approach to mathematics education might help to achieve a school mathematics curriculum that respects local culture. Curriculum which emphasizes local culture may integrate new and more practical mathematical knowledge and skills that may work for the betterment of the local communities. Hence turning to one's own culture to identify the rich mathematical activities that can be incorporated into the school curriculum is the best way to counteract the "compartmentalization" of mathematics through globalization and universalization of mathematics education.

In the following sections we have identified some common everyday math activities from Tamil Nadu and Kerala, two southern states of India. Activities of these sorts can be used in designing curriculum and/or teaching strategies (Moschkovich \& Brenner, 2002). The activities mentioned below include mathematical ideas that involve number, logic, spatial configuration and the combination of these into systems or structures. The mathematical concepts embedded in these every day activities will help students understand and experience classroom mathematics in a meaningful way.

4 Canadian and International Education Vol. 35 no. 1 - June 2006 


\section{Language and Fractions}

Manipulating fractions is the source of much anxiety at all levels of learning. Rampal (2003), however, noticed that in many states of South India, intricate fractions are part of every day vocabulary. In Tamil (the regional language of Tamil Nadu) and Malayalam (the regional language of Kerala), people use complex fractions like half of one fourth ("araikaal") and three fourths of one eighth ("mukaalaraikaal”) in their everyday conversation. Similarly, complex divisions and groupings also exist in rural societies of South India. A rich system of divisions is also essential to the sophisticated system of taal (rhythm) used in Carnatic music (Rampal, 2003). If terms and concepts such as these prevalent in everyday language and art - were incorporated in the curriculum, students could relate to mathematics more easily. Rampal (2003) also noted that non-literate adults use their own oral arithmetic strategies, and are engaged in other mathematical transactions like sorting, measurement and estimation on a daily basis. Similarly poems, narratives, riddles, games and songs about numbers exist in the folklore of the ordinary people. These are not trivial to solve, even with written algorithms. Rampal (2003) mentions a riddle about a sparrow from a flock calling out to one sitting on a tree that says:

"We are not yet hundred strong. We, a similar flock like us, one half of that, a half of that again, and you together make one hundred. How many are we?"

To solve this riddle and get the answer as 36 , we need an equation, but people with an innate mathematical language can solve it orally. Another popular riddle that is used as a part of an oral story but not simple to solve is the following:

If counted in pairs, one will remain,

If counted in threes, two will remain,

If counted in fours, three will remain,

If counted in fives, four will remain,

If counted in seven nothing remains.

(Answer is one hundred and nineteen).

Poems or riddles like this, based on the rhythmic play of words and sounds, meant to tease and challenge the minds of learners, are powerful tools used by traditional oral societies to develop creative thinking and imagination. Gems like these poems or riddles, which are rich in their philosophical and mathematical content, are lost by the children after they start schooling (Rampal, 2003). These poems or riddles, if included in the curriculum, will provide students an experience in solving open-ended problems. These informal activities, once included in the curriculum, can gradually be mathematized and lead to more formal mathematical activity.

\section{Kolam}

The systematic organization of shapes and colors on surfaces is another way that people around the world have imposed spatial ordering on their surroundings. The creation and perception of pattern has a logical as well as aesthetic 
component (Ascher, 1991). Kolam, the rice flower drawings drawn by Tamil women, is an excellent example of the unity of geometrical patterns and aesthetics. These drawings are seen on the floors of buildings and in front of deities in puja (worship) rooms. It serves to decorate the floors and make them look more welcoming. The fractal-like drawings begin with a certain number pattern of points and curved lines around these points. Many of these are completed with a single line drawn in an elegant zig-zag around the entire set of points.

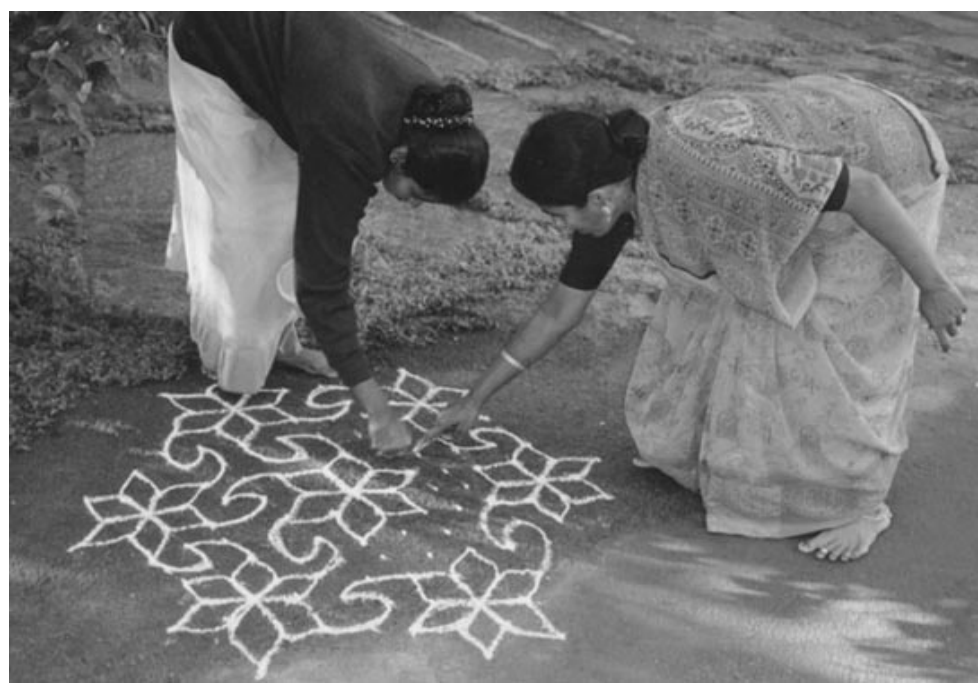

Figure 1: A mother training her daughter to draw kolam

Mahalingam (2000) has noted that these drawings require a complicated understanding of geometrical patterns and spatial reasoning. Kolam includes quite a number of symmetries, horizontal reflections, vertical reflections, translations, rotations, etc. Several different colorings are also associated with these drawings. To become a competent kolam artist, one needs to have both geometrical knowledge and strategic understanding of transferring this knowledge into actual practice. The artist has to make many decisions on the spot depending on the availability of space so that the size of the drawing can be reduced or enlarged in proportion to the available space. In short, the practice of drawing kolam is a complex mathematical activity which involves intuitive and strategic understanding of spatial reasoning (Mahalingam, 2000).

Kolam is a symbol of good fortune. Rice powder used for kolam drawings provides nourishment for smaller animals, such as birds or ants. This is a symbolic act of showing the necessity of sharing and maintaining proper relationships with others. It also reinforces the respect for nature and

6 Canadian and International Education Vol. 35 no. 1 - June 2006 
relationships with other human beings and animals. This art form is almost exclusively practiced by women. They learn to draw kolam from older women in the family.

Even though kolam has entered the realm of computer science (Ascher, 2002), it has so far been ignored by the mathematics education community.
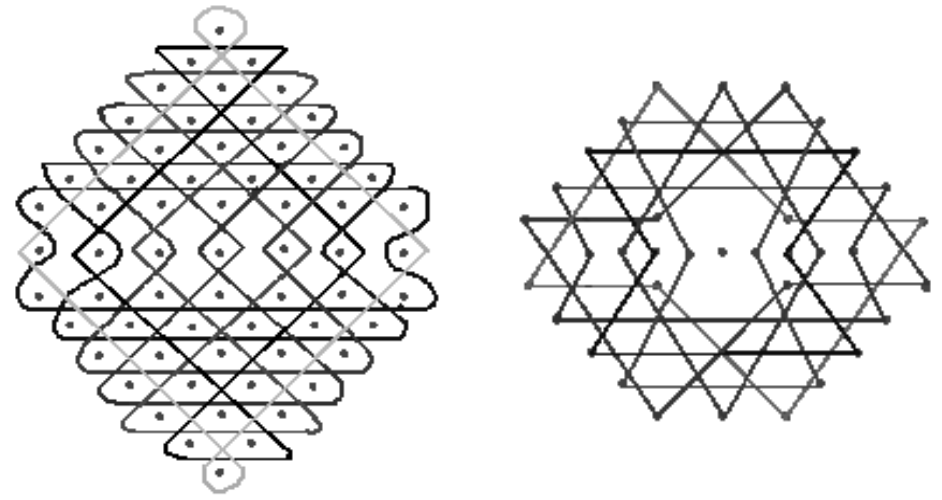

Figure 2: Kolam, a unity of aesthetics and mathematics

\section{Pallanguzhi}

Pallanguzhi is a very old Southern Indian game traditionally played mainly by women. It is also known as Pallam Kuzhi, Pallangulli or Pallankuli. Pala means many and kuzhi means pits, which describes the board used for the game. The material required for this game is a board, usually made of wood, with seven cups or pits on each of its two sides. The boards can be of different shapes. The most popular one is in the shape of a fish (Figure 3). The game beads vary from seeds of tamarind to precious stones depending on how wealthy the players are. Though mainly played by two players, the rules allow four players or partnerships too. Presence of mind, strategy and good memory are needed to win the game. Although different variations of the game are played with this board and bead set, the aim of them all is to collect as many beads as possible, and swipe beads from the opponent's side. Today, this game is played in urban as well as rural areas by both men and women.

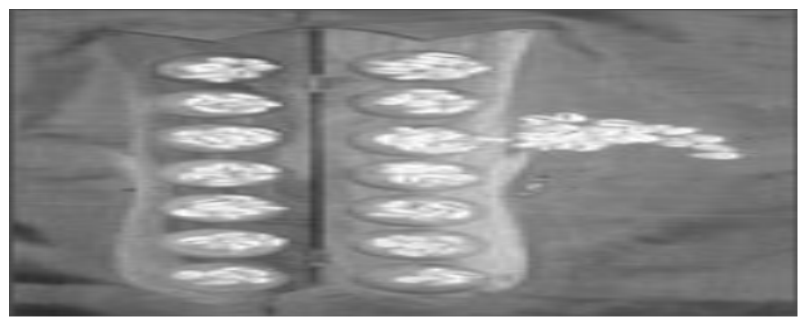

Figure 3: Pallanguzhi board (in the shape of fish) with beads 
The anonymous reviewers of this article noted that a similar version of pallanguzhi is common in Eastern, Southern and Western African culture. It is called Mweso in East Africa. It is slowly becoming common in Western homes also. Mahalingam (2000) has given an account of this game. Each player has seven cups (pits), and each cup contains six beads. The player has to distribute the beads, one per cup, in a clockwise direction. When she has distributed all the beads, she then picks up the next cup and starts again until she reaches an empty pocket. Then the player takes the beads in the cup that is next to the empty cup. The game continues until all cups are emptied. Again the players start with whatever beads they have won. If one player cannot fill all the cups in her side, she fills as many cups as possible and the game continues. The game will continue until one of the players gets all the beads and the other ends up with none. This game involves a complex understanding of distribution and the regrouping of numbers. As in chess, Pallanguzhi also requires an excellent memory for recognizing various positions of the game. For each possible starting position, an expert player knows how many beads she will get if she chooses to start with a particular cup. Players have to visualize the consequences of their starting positions. An expert player will know where to start to get the maximum number of beads at any point in the game (Mahalingam, 2000).

"The Hindu," one of the national news papers of India, reported on the $20^{\text {th }}$ of September, 2003, that in one of the schools of Tiruchi (Sivananda Balalaya), the children are successfully introduced to concepts like division, least common multiple (LCM) and averages through the game of pallanguzhi. However these are "lone voices in the wilderness". In most of the schools, unfortunately, riddles and games practiced by the local people, which are rich in mathematics, are either ignored or trivialized by the mathematics education community.

Abreau (2002) noted that mathematics embedded in cultural activities is not the learning of particular procedures repeated in an automatic, unthinking way, but involves the development of mathematical concepts and processes. This can easily be verified using the above cited examples from South India, which clearly demonstrate the interplay of mathematical ideas and culture. The purpose of this paper is to not to negate or ignore the reforms and efforts of mathematics educators, researchers and organizations such as those championed by National Council of Teachers of Mathematics (NCTM) in North America and Association of Teachers of Mathematics (ATM) in the UK, but to state that there is value in focusing on mathematical ideas of one's own culture and incorporating them into the school curriculum.

\section{Family Math}

The support and participation of parents is required to enrich the learning experience of children. In rural India, most of the parents are either illiterate or have very minimal education. Hence, they are generally not involved in school activities. Most of the time, their ignorance of the curriculum and instruction 
keep them away from school. An important aspect of effective teaching strategy is to build a mathematical community where learners can share mathematical problems and be encouraged by those around them. Through family math activities, the students can be engaged in meaningful homework that would enrich their life in the classroom (Whitin, 2004). This would encourage parents' involvement in school and provide students with an additional opportunity to demonstrate the content and process of classroom mathematics. Moreover, this would create prospects for adults and children to see one another as fellow thinkers.

Classroom teachers in India can use "everyday math” activities, games or puzzles for family math activities. Through this type of family math activity, children will get an opportunity to communicate mathematics to their parents. Parents will also get to share their experience and knowledge about the mathematics they use every day. If parents get an opportunity to broaden their view of mathematics and mathematics learning, through "everyday mathematics activities", their outlook about modern mathematics may change. This change may also encourage them to get more involved in school related activities. Students can be asked to note down any mathematics they use while they talk about or solve these riddles, puzzles or games. This is an excellent way of asking students to reflect on what they learn in their classrooms. Abreau (2002) noted that research in out-of-school activities suggest that children might benefit from approaches that help them to bridge the gap between school mathematics and what they observe and learn outside school.

Additionally, teaching mathematics that builds up from activities like kolam or pallanguzhi, which are considered as "feminine activities," can validate the experience of girls and women and contradict the unfounded notion that they are not able to do mathematics, particularly when involving spatial perception. School mathematics rooted in one's culture, practices and history (Lerman, 1994) could reorient the whole context of mathematics education and allow the learner to experience mathematics as a human rather than an abstract activity.

\section{Conclusion}

Within standardized, broadcast math curricula, concepts and teaching practices are largely dissociated from the knowledge and skills a child brings into the class room. Unless learners realize that mathematics exist in their very own world, beyond school walls and beyond a Eurocentric world view, many of them will continue to complain about it as boring and uninteresting. Universalizing the curriculum for the sake of simplifying assessment or selling textbooks is not going to minimize the anxiety or even hatred that many students feel towards numbers. Conversely, introducing everyday mathematics into curricula will not only help students understand that math is something related to their culture, but will also help them make connections between familiar everyday activities and academic mathematical practices. As well, it will help create a bridge between parents and school, which is a very considerable factor in student success. An 
emphasis on the socio-cultural nature of mathematical knowledge also supports a move away from strictly occidental forms of mathematics teaching and opens the door for more active (e.g.; hands-on, project-based) and constructivist forms of learning.

The authors would like to thank the two anonymous reviewers for their helpful suggestions. Their input made this a better article.

\section{References}

Abreu, G. de. (2002). Mathematics learning in out-of-school contexts: A cultural psychology perspective. In L. D. English (Ed.), Handbook of international research in mathematics education (pp. 323-353). Mahwah, N.J.: Lawrence Erlbaum Associates, Inc.

Anderson, S.E. (1990). Worldmath curriculum: Fighting euro-centrism in mathematics. Journal of Negro Education 59(3), 348-359.

Ascher, M. (1991). Ethnomathematics: A multicultural view of mathematical ideas. Pacific Grove. California: Brooks/Cole Publishing Company.

Ascher, M. (2002). The kolam tradition. American Scientist 90(1), 56-63.

Atweh, B., Clarkson, P \& Nebres, B. (2003). Mathematics education in international and global context. In A. J. Bishop, et.al. (Eds.), Second international handbook of mathematics education, Part one (pp. 185-227). Dordrecht: Kluwer Academic Publishers.

Bishop, A. J. (1988). Mathematical enculturation: A cultural perspective on mathematics education. Dordrecht: Kluwer Academic Publishers.

D'Ambrosio, U. (1993). Ethnomathematics, the nature of mathematics and mathematics education. In P. Ernest (Ed.), Mathematics, education and philosophy: An international perspective (pp. 230-242) London: Falmer Press.

Dowling, P. (1998). The sociology of mathematics education: Mathematical myths/pedagogic texts. London: Falmer Press.

Gates, P. \& Vistro-Yu, C.P. (2003). Is mathematics for all? In A. J. Bishop, et.al. (Eds.), Second international handbook of mathematics education, Part one (pp. 31-73). Dordrecht: Kluwer Academic Publishers.

Gerdes, P. (1997). On culture, geometrical thinking and mathematics education. In A.B. Powell \& M. Frankenstein (Eds.), Ethnomathematics: Challenging eurocentrism in mathematics education (pp. 223-247). Albany: State University of New York Press.

Joseph, G.G. (2000). The crest of the peacock. Non-european roots of mathematics. Princeton: Princeton University Press.

Knijnik, G. (1997). An ethnomathematical approach in mathematical education: A matter of political power. In A.B. Powell \& M. Frankenstein (Eds.), Ethnomathematics: Challenging eurocentrism in mathematics education (pp. 403-410). Albany: State University of New York Press.

Lerman, S. (1994). Cultural perspectives on the mathematics classroom (Ed.), Dordrecht: Kluwer Academic Publishers.

10 Canadian and International Education Vol. 35 no. 1 - June 2006 
Masingila, J. O. (2002). Examining students' perceptions of their every day mathematics practice. Everyday and academic mathematics in the classroom; Journal of research in mathematics education monograph (pp. 30-39). Reston. V.A.: NCTM.

Moschkovich, J.N. \& Brenner, M.E. (2002). Preface. Everyday and academic mathematics in the classroom; Journal of research in mathematics education monograph (pp. v-x). Reston, V.A.: NCTM

Mahalingam, R. ( 2000). Beyond eurocentrism implications of social epistemology for mathematics education? In R. Mahalingam \& C. McCarthy (Eds.), Multicultural curriculum. New directions for social theory, practice and policy (pp. 189-198). New York: Routledge.

National Council of Teachers of Mathematics (NCTM). (1989). Curriculum and evaluation standards for school mathematics. Reston, V.A.: NCTM.

O’Donoghue, J. (2000). Adults, mathematics, culture and society. In D. Coben (Ed.), Perspectives on adults learning mathematics (pp. 101-107). Dordrecht: Kluwer Academic Publishers.

Oldham, E. (1989). Is there an international curriculum? In B. Greer \& G. Mulhern (Eds.), New directions in mathematics education (pp. 185-224). London: Routledge.

Pinxten, R. (1987). Applications in the teaching of mathematics and sciences. In A.B. Powell \& M. Frankenstein (Eds.), Ethnomathematics: Challenging eurocentrism in mathematics education (pp. 373-399). Albany: State University of New York Press.

Rampal, A. (2003). Counting on every day mathematics. In T.S. Saraswati (Ed.), Crosscultural perspectives in human development: theory, research, and applications (pp. 326-353). New Delhi: Sage Publications.

Smith, D. (2000). The specific challenges of globalization for teaching and vice versa. The Alberta Journal of Educational Research. XLVI (1), 7-26.

Stiglitz, J. (2002). Globalization and its discontents. NewYork: W.W. Norton.

Whitin, P. (2004). Enlarging the learning community through family mathematics. In R.N. Rubenstein \& G.W. Bright (Eds.), Perspectives on the teaching of mathematics. Sixty-sixth Yearbook (pp. 117-128). Reston. V.A.: NCTM.

Thomas Varghese is with the Department of Mathematical and Statistical Sciences, University of Alberta, Edmonton, Alberta.

Daniel P. McCusker is a teacher at Vernon Barford School, Edmonton, Alberta. 